\title{
A percepção dos gestores operacionais sobre os impactos gerados nos processos de trabalho após a implementação das melhores práticas de governança de TI no TRE/SC
}

\author{
Rosangela Klumb \\ Tribunal Regional Eleitoral de Santa Catarina \\ Beatriz Marcondes de Azevedo \\ Universidade Federal de Santa Catarina
}

\begin{abstract}
Este estudo objetivou compreender a percepção dos gestores operacionais da Secretaria de Tecnologia da Informação (STI) do TRE/SC acerca dos impactos gerados nos processos de trabalho internos do órgão após a implementação das melhores práticas de governança de TI. Em termos metodológicos, trata-se de um estudo de caso descritivo-avaliativo, de abordagem qualitativa no que concerne às características e ao modo de investigação. Como resultados, verificou-se que até março de 2013 foram implementados oito dos 24 processos de governança de TI baseados no modelo Cobit, versão 4.1, definidos como meta do Planejamento Estratégico de TI para 2013. Concluiu-se que a percepção dos gestores é positiva em relação à governança de TI, embora existam algumas falhas, como na comunicação intra e interáreas e na centralização de informações por alguns setores.
\end{abstract}

Palavras-chave: organizações públicas; governança de TI; Cobit; avaliação de desempenho.

La percepción de los gerentes de operaciones sobre los impactos en los procesos de trabajo después de la implementación de mejores prácticas de gobierno de TI en TRE/SC

Este estudio tuvo como objetivo comprender la percepción de los gerentes de operaciones del Departamento de Tecnología de la Información (ITS) de la TRE/SC de los impactos generados en el funcionamiento interno del cuerpo después de la implementación de mejores prácticas de gobierno de TI. En términos metodológicos, se trata de un caso de estudio descriptivo y evaluativo de un enfoque cualitativo con respecto a las propiedades y el modo de investigación. Como resultado, se encontró que en marzo de 2013 se implementaron ocho de los 24 casos de gobierno de TI basado en Cobit, la versión 4.1, que se define como el objetivo de la planificación estratégica de TI para el 2013 modelo. Se concluyó que la percepción de los directivos es positiva en relación con la gobernanza de TI, aun-

DOI: http://dx.doi.org/10.1590/0034-76121651

Artigo recebido em 23 jul. 2013 e aceito em 7 abr. 2014.

Rev. Adm. Pública - Rio de Janeiro 48(4):961-982, jul./ago. 2014 
que hay algunos defectos, por ejemplo, la comunicación dentro y entre áreas y centralización de la información por parte de algunos sectores.

Palabras clave: organizaciones públicas; gobernanza de la TI; Cobit; evaluación del desempeño.

The perception of operational managers on the impacts on work processes after the implementation of best practices in IT governance in the Regional Court of Santa Catarina (TRE/SC) This study aims to understand the perception of the operational managers of the Department of Information Technology (ITS) of TRE/SC over the impacts created in the internal working processes of the body after the implementation of best practices in IT governance. In methodological terms, it is a descriptive-evaluative study case of a qualitative approach concerning the characteristics and way of investigation. As a result, it was identified that by March 2013, there were implemented eight of the 24 cases of IT governance processes based on Cobit model, Version 4.1, defined as the goal of Strategic IT Planning for 2013 model. It was concluded that the perception of managers is positive in relation to IT governance, although there are some flaws, as in the communication within and between areas, and in the centralization of information by some sectors.

KEYWORDs: public organizations; IT governance; Cobit; performance evaluation.

\section{Introdução}

O papel da tecnologia da informação (TI), a partir dos avanços tecnológicos da metade do século XX, migrou de um provedor de tecnologia para um parceiro estratégico, adotando modelos administrativos de estruturação que levam necessariamente à modificação da forma de atuação dos seus profissionais, incorporando novos conhecimentos sobre seus processos, a fim de promover a geração e a disseminação do conhecimento entre equipes (Carvalho, 2005).

A TI tornou-se, portanto, essencial para que as organizações mantenham um processo decisório efetivo e um controle sobre suas operações. Todavia, essa tecnologia trouxe também uma série de processos relacionados à sua gestão e manutenção, exigindo que aspectos relativos à qualidade, como eficiência, eficácia e efetividade das informações, sejam controlados (Tarouco e Graeml, 2011). Dessa forma, as organizações, segundo ITGI (2007), não podem atingir seus requisitos de negócios e governança sem adotar e implementar um modelo para governança de TI.

Nesse contexto, surge o tema da governança de TI que, através de modelos de melhores práticas em gestão de TI, propõe caminhos para que os serviços tragam apoio efetivo ao negócio, tanto do ponto de vista dos seus usuários internos quanto dos clientes externos. Além do mais, órgãos controladores vêm exigindo, por meio de novas regras, a adoção de modelos de melhores práticas, normas de contratação de serviços de TI e gestão de fornecedores de serviços (FQN, 2010; TCU, 2008; Van Bon, 2009; TCU, 2010).

Para Fagundes (2009), as soluções de melhoria da gestão da TI nas empresas têm levado essas a combinarem gestões, compartilharem decisões e criarem a governança corporativa para a TI. 
No entanto, Sethibe, Campbell e McDonald (2007) apontam a necessidade de se distinguir gestão e governança de TI. Para eles, a diferença reside no foco e no lócus das atividades. Assim, enquanto a gestão foca o ambiente interno da organização e é realizada no nível departamental, a governança de TI intercala o foco interno e externo e deve ser realizada em nível hierárquico superior, contemplando a organização como um todo.

Segundo Fernandes e Abreu (2008), Tarouco e Graeml (2011) e Preis (2011), a expressão modelo de melhores práticas é sinônimo de práticas padronizadas, independentemente de serem melhores do que outras passíveis de serem utilizadas.

Ainda em relação aos modelos estruturais de gestão de TI, Rodrigues, Maccari e Simões (2009) realizaram um estudo para identificar o desenho do gerenciamento da TI nas 100 maiores empresas brasileiras. Dentre os modelos mais adotados por tais organizações identificados pelos autores, assumiram a liderança o Itil e o Cobit. O mesmo foi confirmado nos achados da pesquisa de Lunardi e Dolci (2009).

Conforme Tarouco e Graeml (2011), a preocupação com controle e qualidade dos serviços prestados pela TI justifica que o Itil seja amplamente utilizado pelas empresas; enquanto a utilização das práticas de gestão do Cobit é justificada pela possibilidade de auxiliar na otimização dos investimentos em TI, fornecendo assim métricas para avaliação dos resultados (ITGI, 2007).

O Cobit, portanto, representa um framework de governança de TI e uma ferramenta de suporte que permite aos gestores relacionar as exigências de controle, as questões técnicas e os riscos do negócio, possibilitando o desenvolvimento de políticas claras e boas práticas para o controle de TI (Isaca, 2010).

Estudos recentes comprovam que organizações que adotaram mecanismos de governança de TI melhoraram seu desempenho financeiro, comparando indicadores de desempenho pré e pós a adoção (Tarouco e Graeml, 2011; Lunardi, Becker e Maçada, 2012).

Sethibe, Campbell e McDonald (2007) afirmam que, no entanto, há várias diferenças entre a atuação do setor privado e a do setor público, embora ambos busquem melhorar seu desempenho quer na obtenção de lucro (setor privado), quer na eficiência, eficácia e efetividade na prestação dos serviços públicos (setor público).

No setor público, foram realizados recentemente, pelo Tribunal de Contas da União (TCU), dois levantamentos de governança de TI na Administração Pública Federal (APF). O primeiro em 2007, realizado com 255 instituições públicas federais, e o segundo em 2010, com 315 instituições. O resultado constatou a precariedade da governança de TI na APF, havendo, inclusive, desconhecimento de conceitos básicos sobre o tema. Verificou-se também que instituições que geram expressivas quantias de recursos financeiros não apresentam boa governança de TI, o que sugere um risco na gestão do dinheiro público (TCU, 2010).

A partir desse levantamento, foram definidas algumas recomendações ao Conselho Nacional de Justiça (CNJ) no sentido de dar orientações às instituições sob seu controle para que, baseadas no princípio da eficiência, do planejamento e do controle, essas organizações estabeleçam formalmente objetivos institucionais de TI alinhados às estratégias do negócio; 
indicadores para cada objetivo definido; metas para cada indicador definidas, bem como mecanismos para o acompanhamento do desempenho institucional (TCU, 2010).

Diante dessa realidade, em 2009, o Tribunal Regional Eleitoral de Santa Catarina (TRE/ SC) adotou as primeiras medidas no sentido de implementar a governança de TI. Para tanto, alguns processos de gerenciamento de serviços de TI foram mapeados e implementados e alguns objetivos, metas e indicadores de desempenho foram definidos. Como consequência, foi possível monitorar as evoluções ocorridas, bem como alterar os fluxos de trabalho e as rotinas do órgão no sentido de maximizar a eficiência organizacional.

Embora as recomendações do CNJ tenham sido atendidas, questiona-se qual o impacto que tais mudanças trouxeram para o TRE/SC e se ocorreram benefícios para o órgão ou apenas tornaram os processos de trabalho mais "burocráticos".

Para buscar compreender os reflexos da implementação da governança em TI no TRE/ SC, procurou-se, com a realização do presente estudo, construir conhecimentos que permitissem responder ao seguinte questionamento: como a implementação das melhores práticas de governança de TI tem impactado nos processos internos de trabalho da organização, na percepção dos gestores operacionais da Secretaria de Tecnologia da Informação?

Assim, objetivou-se neste estudo compreender os impactos gerados nos processos de trabalho internos do TRE/SC, após a implementação das melhores práticas de governança de TI, a partir da percepção dos gestores operacionais.

\section{Organizações públicas}

O termo público pode ser entendido, segundo Keinert (2007:61), como relativo àquilo que "é de todos e para todos", à "coisa pública" (res publica) e ao "interesse público". Concerne, ainda, às relações econômicas, políticas e sociais que interferem na produção do espaço público. Dessa forma, os diferentes conceitos de "público" envolvem questões de poder, de legitimidade, de valores.

O Brasil se organiza administrativamente em: União, estados, Distrito Federal e municípios, cada qual com sua autonomia (Brasil, 2013). A atividade do Estado dirigida à consecução das necessidades coletivas de modo direto e indireto denomina-se Administração Pública, que, como todas as organizações administrativas, é baseada em uma estrutura hierarquizada com graduação de autoridade, correspondente às diversas categorias funcionais (Brandião et al., 2008).

A Administração Direta é representada por pessoas de direito público com capacidade política, como União, estados, Distrito Federal e municípios, sendo a gestão dos serviços públicos realizada por pessoas políticas por intermédio de seus órgãos. A Administração Direta é constituída pelos órgãos dos Poderes Executivo, Legislativo e Judiciário (Brandião et al., 2008).

Nesse aspecto, as organizações públicas mantêm as mesmas características das demais organizações, acrescidas de algumas especificidades como: apego às regras e rotinas, super- 
valorização da hierarquia, paternalismo nas relações, apego ao poder, entre outras. Tais diferenças são importantes na definição dos processos internos, na relação com inovações e mudanças, na formação dos valores e crenças organizacionais e na política de recursos humanos (Pires e Macêdo, 2006).

O Poder Judiciário possui a função de garantir os direitos individuais, coletivos e sociais e resolver conflitos entre cidadãos, entidades e Estado, contando, para isso, com autonomia administrativa e financeira, garantidas pela Constituição Federal. Dentre os órgãos que o compõem, está a justiça eleitoral, que, com o objetivo de garantir o direito ao voto direto e sigiloso, preconizado pela Constituição, regulamenta os procedimentos eleitorais. Na prática, é responsável por organizar, monitorar e apurar as eleições, bem como por diplomar os candidatos eleitos. Também pode decretar a perda de mandato eletivo federal e estadual e julgar irregularidades praticadas nas eleições (Brasil, 2013).

\section{Governança de TI}

A governança de TI constitui um subconjunto da governança corporativa, podendo ser conceituada, segundo Rohweder (2007) e IBGC (2009), como o sistema pelo qual as organizações são dirigidas, monitoradas e incentivadas, envolvendo os relacionamentos entre proprietários, Conselho de Administração, Diretoria e órgãos de controle, e possui como objetivo o atendimento da alta administração e do negócio nas questões relacionadas à TI.

Para alguns autores como Rohweder (2010) e Alvares e colaboradores (2008), o conceito de governança transcende a prática de comando de um ambiente formado por tecnologias, pessoas e processos. Ao transferi-la para o universo corporativo, a governança pode assegurar que as organizações atendam às determinações dos seus principais stakeholders, garantindo sua continuidade e operação.

Da mesma forma, o Instituto de Governança de Tecnologia da Informação (ITGI, 2007:7) a define como "uma estrutura de relacionamentos e processos, para dirigir e controlar a organização no sentido de atender os objetivos dessa organização, adicionando valor, ao mesmo tempo em que equilibra os riscos em relação ao retorno da TI e seus processos". Para o Instituto, a governança de TI "é de responsabilidade dos executivos e da alta direção, consistindo em aspectos de liderança, estrutura organizacional e processos que garantam que a área de TI da organização suporte e aprimore os objetivos e as estratégias da organização" (ITGI, 2007:7).

Weill e Ross (2006:8), por sua vez, entendem governança de TI como "a especificação dos direitos decisórios e do framework de responsabilidades para estimular comportamentos desejáveis na utilização da TI". Segundo os autores, o conceito trata de dois aspectos simples: direitos decisórios e responsabilidade, que diferem de organização para organização. Enquanto governança determina o responsável pela tomada de decisão, administração é o processo de tomar decisões e implementá-las. 
Jaeger-Neto e colaboradores (2009) e Tarouco e Graeml (2011) afirmam que a governança corporativa e a de TI podem influenciar significativamente no desempenho da organização, por meio da geração de valor para o negócio e da gestão equilibrada do risco com o retorno do investimento.

Para garantir que a área de TI suporte os objetivos de negócios, a governança de TI integra e institucionaliza boas práticas, habilita a organização a obter todas as vantagens de sua informação, "maximizando os benefícios, capitalizando as oportunidades e ganhando em poder competitivo" (ITGI, 2007:8). O ITGI (2007) entende como elementos-chave que constituem a governança de TI: a avaliação do valor de TI, o gerenciamento dos riscos relacionados à TI e às crescentes necessidades de controle sobre as informações.

Fernandes e Abreu (2008:15) ampliam esses conceitos, destacando que a governança de TI busca, além do compartilhamento das decisões de TI com os demais dirigentes da organização, o estabelecimento de regras de organização e dos processos que norteiam o uso da tecnologia da informação pelos usuários, departamentos, divisões, negócios da organização, fornecedores e clientes, e ainda determina como a TI deve prover os serviços para a organização. Nesse aspecto, a Governança de TI deve atender, segundo os autores, aos seguintes requisitos: a) garantir o alinhamento da TI ao negócio; b) garantir a continuidade do negócio contra interrupções e falhas; c) garantir o alinhamento da TI aos marcos de regulação externos.

Rossi (apud Adachi, 2008) destaca três diferentes abordagens para formular uma definição de governança de TI, quais sejam:

a) Abordagem baseada no alinhamento estratégico entendido como um processo contínuo de adaptação e mudança, que pode garantir o alinhamento entre os domínios de TI e do negócio da organização, e que pode ser a chave para se determinar o valor trazido pelos investimentos em TI;

b) Abordagem baseada em papéis e responsabilidades que se utiliza de mecanismos práticos de identificação, avaliação e implementação de controles de TI; e

c) Abordagem baseada em processos que formam a governança de TI, ou seja, o conjunto de processos que gerenciam os recursos de TI com objetivo de fornecer informações confiáveis à organização para que os objetivos estratégicos sejam alcançados.

A partir dessas considerações, Rossi (apud Adachi, 2008) define a governança de TI como o sistema formado por regras, processos e estruturas que busca garantir a efetividade nas tomadas de decisão relacionadas à TI.

Cabe destacar que a governança de TI pode ser atingida por meio de um conjunto de melhores práticas (Rodríguez e Vieira, 2007), dentre as quais têm-se:

a) Cobit: guia para a gestão de TI que fornece informações detalhadas para gerenciar processos baseados nos objetivos de negócios;

b) Itil (Information Technology Infrastructure Library): conjunto de melhores práticas para gerir o planejamento, gerenciamento de incidentes e problemas, mudanças, configurações, operações, capacidade, disponibilidade e custos dos serviços de TI; 
c) BS7799 (Information Security Standard)/ISO 17799/ISO 27001: tratam de normas para segurança da informação em TI, abrangendo os aspectos de segurança física do ambiente, passando por pessoas e detalhando cuidados essenciais das questões relacionadas à rede de comunicação, aos aplicativos e ao acesso remoto;

d) CMM/CMMI (Capability Maturity Model/Capability Maturity Model Integration): certificação concedida pelo Software Engeneering Institute (SEI), da Universidade de Carnegie Mellon (USA), que mede o grau de maturidade no processo de desenvolvimento de software. No Brasil, tem-se uma adaptação desse modelo, conhecido como MPS.BR (Melhoria do Processo de Software Brasileiro).

Os modelos não são excludentes, pelo contrário, podem ser integrados para se obter um maior gerenciamento de TI (Mingay e Bittinger apud Rodríguez e Vieira, 2007).

Ressalta-se que o Tribunal Regional Eleitoral de Santa Catarina adota como práticas de gerenciamento de serviços de TI e de governança: Cobit, Itil, MPS.BR e normas de Segurança da Informação, porém neste estudo foram considerados os processos relacionados ao Cobit.

\section{Cobit}

O Cobit foi criado em 1994 pela Information Systems Audit and Control Foundation (Isaf), a partir de objetivos iniciais de controle que foram recebendo incorporações de padrões internacionais técnicos, profissionais, regulatórios e específicos para os processos de TI (Fernandes e Abreu, 2008). O modelo apresenta foco orientado "a uma maior eficácia dos objetivos de controle e dos processos de verificação e divulgação dos resultados” (Fernandes e Abreu, 2008:174).

Segundo os princípios do ITGI (2007), as informações corporativas e a tecnologia necessária para suportá-las não podem ser tratadas isoladamente, devendo a TI ser parte integrante da estratégia corporativa, em vez de apenas um meio de viabilizá-la.

A partir da perspectiva das necessidades do negócio, mais focado no controle do que na execução, o principal objetivo das práticas do Cobit é contribuir para o sucesso da entrega de bens e serviços de TI. O modelo possibilita, a partir disso, estabelecer relacionamentos com os requisitos do negócio, organizar as atividades de TI em um modelo de processo genérico, identificar os principais recursos de TI, que exigem maiores investimentos, e definir os objetivos de controle considerados para a gestão.

A intenção do Cobit é, portanto, prover boas práticas através de um framework de domínios e processos e apresentar atividade em uma estrutura lógica gerenciável (Luciano e Testa, 2011). Os autores afirmam ainda que o Cobit tenta garantir a governança de TI provendo um framework que assegure quatro aspectos principais: que a TI esteja alinhada com o negócio; que a TI torne o negócio possível e maximize seus benefícios; que os recursos de TI sejam utilizados com responsabilidade; e que os riscos associados a TI sejam gerenciados de maneira apropriada. 
A primeira área do Cobit relaciona-se: a) ao alinhamento estratégico (que garante a ligação entre os planos de negócio e de TI, a manutenção e validação da proposição de valor da TI, e o alinhamento das operações da organização com as de TI); b) à agregação de valor (associando-a ao tempo, assegurando a entrega dos benefícios oferecidos pela TI, de acordo com a estratégia estabelecida, concentrando-se em otimizar custos e comprovar o valor intrínseco da TI); c) ao gerenciamento de recursos (gestão adequada dos recursos críticos de TI, necessários para fornecer subsídios suficientes para atingir seus objetivos); d) ao gerenciamento de riscos (envolve o conhecimento dos riscos pela alta direção, o entendimento básico dos requisitos de conformidade, transparência sobre os riscos significativos para a organização, assim como a incorporação de responsabilidades para o gerenciamento de riscos); e e) à medição de desempenho (refere-se ao acompanhamento e monitoramento da implementação da estratégia, do andamento do projeto, da utilização de recursos, do desempenho de processos e da entrega de serviços, utilizando indicadores de desempenho que traduzem estratégias em ações para atingir objetivos mensuráveis).

A implantação de forma integrada da governança de TI permite que a organização disponha de eficiência no gerenciamento dos seus investimentos em recursos tecnológicos e das suas informações, propiciando a transformação de informações em maximização de benefícios, oportunidades de negócio e vantagem competitiva (Fernandes e Abreu, 2008).

Assim, o Cobit possui, como principais características, o foco nos requisitos do negócio, a orientação para abordagem de processos, a utilização de mecanismos de controle e o direcionamento para a análise das medições e indicadores de desempenho obtidos ao longo do tempo, conforme pode ser observado na figura 1.

Figura 1

Princípio básico do Cobit

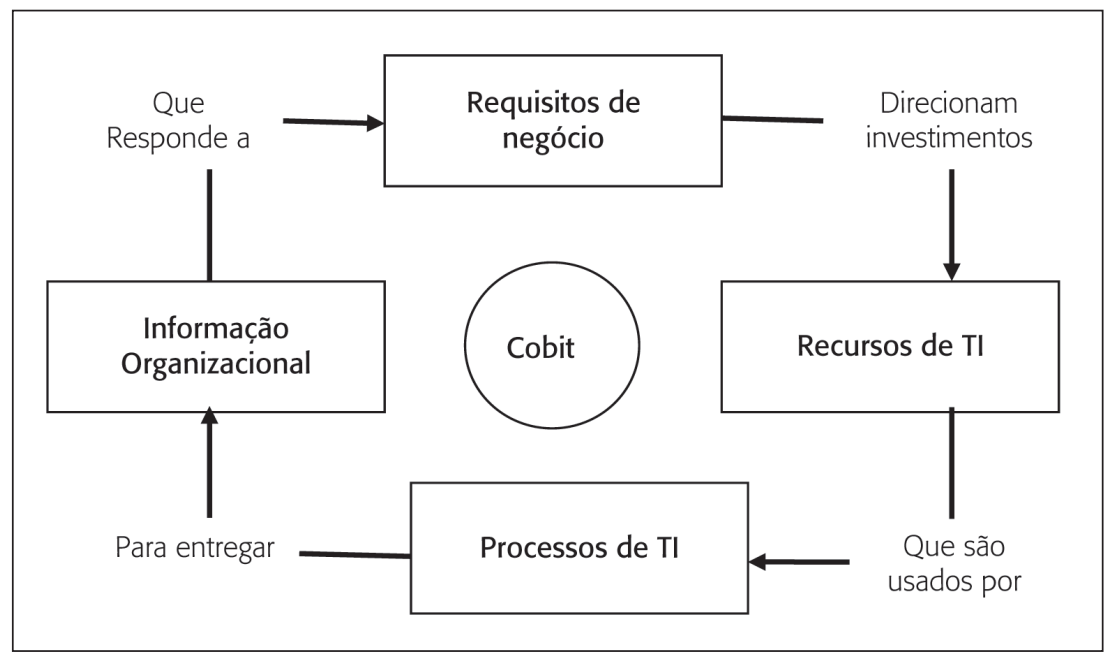

Fonte: ITGI (2007). 
Ainda, em relação aos serviços que fornecem as informações necessárias para que a organização atinja seus objetivos, esses são disponibilizados por meio de um conjunto de processos de TI, que utilizam, por sua vez, recursos de TI, ou seja, pessoas com habilidades, conhecimentos e índices de produtividade, e infraestrutura para executar aplicações automatizadas e manuais que manipulam e processam informações de negócio. O intuito desses investimentos é promover capacitação técnica que refletirá nos resultados estratégicos.

O framework do Cobit v. 4.1 identificou 34 processos de TI e os distribuiu entre quatro domínios, que espelham os agrupamentos usuais existentes em uma organização padrão de TI, domínios esses ilustrados no quadro 1.

\begin{tabular}{|c|c|}
\hline Domínio & Processos de $\mathrm{TI}$ \\
\hline 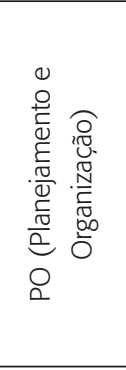 & $\begin{array}{l}\text { PO-1 - Definir um plano estratégico para a TI } \\
\text { PO-2 - Definir a arquitetura da informação } \\
\text { PO-3 - Determinar direcionamento tecnológico } \\
\text { PO-4 - Definir a organização de TI, seus processos e relacionamentos } \\
\text { PO-5 - Gerenciar o investimento em TI } \\
\text { PO-6 - Comunicar objetivos e direcionamentos gerenciais } \\
\text { PO-7 - Gerenciar os recursos humanos } \\
\text { PO-8 - Gerenciar a qualidade } \\
\text { PO-9 - Avaliar e gerenciar riscos de TI } \\
\text { PO-10 - Gerenciar projetos }\end{array}$ \\
\hline 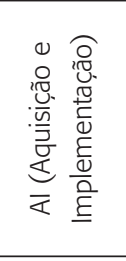 & $\begin{array}{l}\text { Al-1 - Identificar soluções automatizadas } \\
\text { Al-2 - Adquirir e manter software aplicativo } \\
\text { Al-3 - Adquirir e manter infraestrutura tecnológica } \\
\text { Al-4 - Viabilizar operação e utilização } \\
\text { Al-5 - Adquirir recursos de TI } \\
\text { Al-6 - Gerenciar mudanças } \\
\text { Al-7 - Instalar e aprovar soluções e mudanças }\end{array}$ \\
\hline 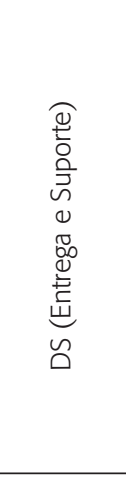 & $\begin{array}{l}\text { DS-1 - Definir e gerenciar níveis de serviço } \\
\text { DS-2 - Gerenciar serviços terceirizados } \\
\text { DS-3 - Gerenciar desempenho e capacidade } \\
\text { DS-4 - Garantir a continuidade dos serviços } \\
\text { DS-5 - Garantir a segurança dos sistemas } \\
\text { DS-6 - Identificar e alocar custos } \\
\text { DS-7 - Educar e treinar usuários } \\
\text { DS-8 - Gerenciar Central de Serviços e incidentes } \\
\text { DS-9 - Gerenciar configuração } \\
\text { DS-10 - Gerenciar problemas } \\
\text { DS-1 } 1 \text { - Gerenciar dados } \\
\text { DS-12 - Gerenciar ambiente físico } \\
\text { DS-13 - Gerenciar operações }\end{array}$ \\
\hline 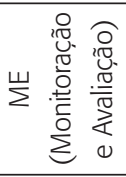 & $\begin{array}{l}\text { ME-1 - Monitorar e avaliar o desempenho da TI } \\
\text { ME-2 - Monitorar e avaliar os controles internos } \\
\text { ME-3 - Assegurar conformidade com requisitos externos } \\
\text { ME-4 - Fornecer governança para a TI }\end{array}$ \\
\hline
\end{tabular}

Fonte: Fernandes e Abreu (2008). 
Com base no quadro 1, Fernandes e Abreu (2008:178) conceituam esses domínios do modelo Cobit como:

a) Planejamento e Organização (PO): possui abrangência estratégica e tática e identifica as formas mediante as quais a TI pode contribuir melhor para atingir os objetivos do negócio, envolvendo planejamento, comunicação e gerenciamento em diferentes perspectivas;

b) Aquisição e Implementação (AI): está relacionado à identificação, ao desenvolvimento ou à aquisição de TI para executar a estratégia de TI estabelecida, ao modo de realizar sua implementação e integração junto aos processos de negócio, bem como a mudanças executadas para garantir a continuidade dos ciclos de vida dos domínios;

c) Entrega e Suporte (DS): refere-se à entrega dos serviços requeridos, incluindo gerenciamento de segurança e continuidade, suporte aos serviços para os usuários, gestão dos dados e da infraestrutura operacional; e

d) Monitoramento e Avaliação de Desempenho de TI (ME): visa a assegurar a qualidade dos processos de TI, assim como sua governança e conformidade com os objetivos de controle, por meio de mecanismos regulares de acompanhamento, monitoramento e controle internos, bem como de avaliações internas e externas.

Cabe destacar que os objetivos de controle do Cobit procuram atestar como cada processo faz uso dos recursos de TI para atender de forma primária ou secundária cada requisito do negócio em termos de informação, cobrindo todos os aspectos. Além disso, assinala-se que o Cobit fornece informações detalhadas sobre o gerenciamento dos processos, possibilitando o monitoramento de quanto a TI está agregando valor ao negócio da organização, independente da plataforma de TI adotada pela organização (Luciano e Testa, 2011).

\section{Avaliação de desempenho}

O termo avaliação pode ser definido intuitivamente de diferentes maneiras, dependendo do tipo de uso. No entanto, para os profissionais da avaliação não é tarefa fácil, sendo o conceito preferido o estabelecido por Scriven (apud Worthen et al., 2004), que a definiu como "julgar o valor ou mérito de alguma coisa".

Segundo Worthen e colaboradores (2004:35), uma definição mais extensa de avaliação é "identificação, esclarecimento e aplicação de critérios defensáveis para determinar o valor (valor ou mérito), a qualidade, a utilidade, a eficácia ou a importância do objeto avaliado em relação a esses critérios". Os autores afirmam que a avaliação utiliza métodos de pesquisa e julgamento para: determinar padrões de qualidade; coletar informações relevantes; aplicar os padrões para determinar o valor, a qualidade, a utilidade, a eficácia ou a importância. Tudo isso produz informações que geram recomendações de melhoria do objeto avaliado. 
Para Dumont e colaboradores (2006), o conceito de avaliação de desempenho público, tradicionalmente concentrado na avaliação de contas públicas, tem evoluído no sentido de medir, além dos aspectos contábeis, aspectos econômicos e sociais, priorizando os resultados alcançados relacionados à evolução das condições sociais da população.

Segundo os mesmos autores, busca-se hoje a eficácia, a eficiência e a efetividade na aplicação dos recursos públicos por parte dos administradores, por meio de métodos de avaliação que destaquem a sociedade como cliente primeiro do setor público, minimizando a distância entre os anseios da população e os objetivos principais das organizações públicas.

Nesse contexto, os novos modelos de avaliação de resultados devem permitir aos seus gestores e aos seus fiscalizadores a visualização do cenário no qual estão inseridos, a fim de avaliar se a trajetória desejada está sendo seguida ou se é necessário corrigi-la. Além disso, o contínuo aprimoramento das técnicas de avaliação de resultados permitirá atingir o objetivo maior de qualquer governo que é a maximização do bem-estar social, assim como permitirá aos gestores o cumprimento das exigências legais impostas pela Constituição Federal.

A avaliação de desempenho é um instrumento, um meio para atingir os objetivos organizacionais e, para tanto, é fundamental o resgate da função planejamento para o cumprimento da sua finalidade de promover a efetividade, a eficácia e a eficiência da ação governamental. Nesse ínterim, a efetividade deve ser entendida como a qualidade do que atinge seu objetivo; é a capacidade de funcionar normalmente, adequadamente, porém relaciona-se com a realidade, com o verdadeiro; enquanto a eficácia refere-se ao atingimento dos objetivos perseguidos, com a realização perfeita de determinada tarefa ou função, produzindo o resultado pretendido. Já a eficiência diz respeito à qualidade de fazer com excelência, sem perdas ou desperdícios (Dumont et al., 2006).

A fim de atingir a função de instrumento de medida e de avaliação são utilizados indicadores - definidos como instrumentos de medição usados para indicar mudanças na realidade social em análise, ou seja, são uma régua ou um padrão que ajuda a medir, avaliar ou demonstrar variações em alguma dimensão da realidade, relevante para os objetivos de um determinado projeto, cujas principais características são: simplicidade, baixo custo de obtenção, estabilidade e confiabilidade (Armani, 2008). Para o autor, é fundamental a qualidade dos indicadores utilizados para avaliar o progresso de um projeto.

\section{Procedimentos metodológicos}

Esta pesquisa caracteriza-se como um estudo de caso descritivo-avaliativo, de abordagem qualitativa no que concerne às características e ao modo de investigação sobre o fenômeno a ser pesquisado.

A pesquisa foi dividida em duas etapas: na primeira se procurou identificar os processos de governança implementados no TRE/SC, bem como os indicadores de desempenho relacionados a cada processo; e na segunda se buscou compreender a percepção dos gestores operacionais da STI do TRE/SC sobre o impacto causado pela implementação na governança de TI 
nos processos internos de trabalho da organização. Adotou-se como instrumentos de coleta de dados a observação participante, a pesquisa documental e a entrevista semiestruturada.

A primeira etapa da pesquisa foi realizada por meio de pesquisa documental a partir de relatórios de acompanhamento do Planejamento Estratégico de TI do órgão; relatórios extraídos dos sistemas de informação do TRE/SC, bem como os Relatórios de Atividades desenvolvidas pelo TRE/SC nos anos de 2010 a 2012.

A análise documental ocorreu, conforme definido por Zanella (2009), em três fases, a saber: a) pré-análise (escolha e organização do material): foram definidos os documentos utilizados para identificação das informações necessárias à pesquisa, ou seja, o Relatório de acompanhamento do Planejamento Estratégico de TI, Sistemas de informações do TRE/SC e Relatórios de Atividades do TRE/SC; b) descrição analítica dos dados coletados: com base nas informações presentes no quadro 1, foram identificados nos documentos os processos mapeados; e c) interpretação dos resultados: fez-se a articulação do conteúdo do material analisado com a base teórica referencial, buscando torná-lo significativo e válido, identificando-se, nesta etapa, os indicadores associados a cada processo mapeado.

A partir da identificação dos processos Cobit mapeados no TRE/SC, partiu-se para a segunda etapa da pesquisa. Para tanto, adotou-se como instrumento de coleta de dados a aplicação de um roteiro de entrevista semiestruturada em que foi utilizado o processo de amostragem não probabilística, em que os sujeitos da pesquisa foram chefes de seção que compõem a Secretaria de Tecnologia de Informação (STI) do TRE/SC, totalizando seis participantes. Assim, aplicou-se a técnica de observação participante e um roteiro de entrevista semiestruturada com os chefes de seção visando a compreender o processo de implementação da governança de TI no TRE/SC e as possibilidades de melhorias identificadas por esses gestores.

A partir da triangulação dos dados, foi possível observar fatos e fenômenos relacionados à prática da governança de TI verificados no TRE/SC, associando-se essa realidade à fundamentação teórica consistente - o que possibilitou a compreensão e a explicação de como a governança de TI é adotada na organização, quais os impactos gerados e as melhorias a serem propostas.

Destaca-se que o processo de governança de TI aqui considerado contempla 34 processos que estão divididos em quatro domínios do Cobit: planejamento e organização (PO); aquisição e implementação (AI); entrega e suporte (ES) e monitoração e avaliação (ME), apresentados no quadro 1.

De posse dos dados coletados ao longo da pesquisa, os mesmos foram organizados, tratados e analisados tomando como base categorias delimitadas nesse estudo: governança de TI, processos de governança de TI, indicadores de desempenho. É importante mencionar que os elementos contidos no quadro 1 também serviram como ponto de partida para apresentação e discussão dos resultados obtidos.

\section{Análise e interpretação dos dados}

Primeiramente tem-se o resultado da pesquisa documental, cujo propósito foi identificar os processos de governança de TI implementados no TRE/SC no período compreendido entre 
março de 2010 e março de 2013, bem como os indicadores de desempenho definidos e efetivamente mensurados para cada processo de governança de TI implementado. Em seguida, apresentam-se os dados, obtidos por meio da entrevista, sobre a percepção dos gestores operacionais da STI acerca da implementação da governança de TI no TRE/SC. A partir dessas informações buscou-se confrontá-las com o referencial teórico pesquisado visando a avaliar o real impacto gerado pela implementação da governança de TI no TRE/SC nos processos de trabalho interno da organização.

A partir dos dados obtidos com a pesquisa documental, verificou-se que o Planejamento Estratégico de TI então vigente previa como meta relacionada ao objetivo estratégico Eficiência Operacional "aplicar os princípios de governança de TIC". Esse objetivo visava a garantir que 28 dos 34 processos Cobit estivessem classificados com o nível de maturidade gerenciado e mensurado até o ano de 2014. Para tanto, dentre as ações estabelecidas para atingir esse objetivo estratégico estava a de implantar os processos do modelo Cobit, versão 4.1, que previa a implementação de três processos até dezembro de 2010, 10 até dezembro de 2011, 14 até 2012, 24 até 2013 e 28 em 2014.

Durante a primeira etapa de coleta dos dados, verificou-se que, dos 24 processos de TI relacionados à governança de TI preconizados pelo Cobit e definidos como meta a ser atingida pelo TRE/SC até dezembro de 2013, oito haviam sido implementados até março de 2013, a saber: DS1: definir e gerenciar nível de serviço, DS8: gerenciar a Central de Serviços de TI e incidentes, DS9: gerenciar a configuração, DS10: gerenciar problemas, PO1: definir Plano Estratégico de TI, PO10: gerenciar projetos (desenvolvimento de software) e AI7: instalar e homologar soluções e mudanças, conforme apresentado no quadro 2.

A partir do quadro 2, pode-se observar que, no entanto, apenas dois tipos de processos Cobit possuíam indicadores de desempenho definidos, mensurados e divulgados (DS8 e AI6). Observa-se ainda que o primeiro processo possui seis indicadores e o segundo apenas um. Embora o número não seja expressivo, ele assume significativa importância uma vez que esses processos estão relacionados diretamente à entrega de serviços de TI aos usuários e, consequentemente, à sociedade. Esse achado vai ao encontro da afirmação de Alvares e colaboradores (2006) de que a aplicação dos recursos públicos por parte dos gestores públicos deve primar pela eficiência, eficácia e efetividade, por meio de métodos de avaliação que priorizem a sociedade como principal cliente do serviço público.

Os indicadores de desempenho mensurados no TRE/SC relacionam-se à economicidade, à eficiência e à eficácia dos serviços de TI, conforme já destacado por Van Bon e colaboradores (2009). Entretanto, Rodrigues, Maccari e Simões (2009) chamam atenção para o fato de que, apesar de o Cobit garantir padrões internos, documentação, monitoramento e medida dos indicadores de qualidade, ele pode ainda se distanciar das melhores práticas automatizadas do mercado, caso seus processos não forneçam indicadores de desempenho para os negócios. Portanto, além de a gestão possuir controles internos de qualidade, é imprescindível que eles sejam validados pelos gestores e sejam auditados externamente. 
Quadro 2

Processos implementados no TRE/SC e indicadores relacionados

\begin{tabular}{|c|c|c|}
\hline Ano & Processo implementado & Indicador(es) relacionado(s) \\
\hline 2010 & DS8 - Gerenciar a Central de Serviços de TI e incidentes & $\begin{array}{l}\text { Número de ocorrências registradas } \\
\text { Tempo Médio de resolução (h) } \\
\text { Índice de incidentes reabertos } \\
\text { Índice de resolução por nível (\%) } \\
\text { Índice de aberturas Web } \\
\text { Índice de eventos de hardware (\%) }\end{array}$ \\
\hline & $\begin{array}{l}\text { DS9 - Gerenciar a configuração } \\
\text { PO1 - Definir Plano Estratégico de TI }\end{array}$ & \\
\hline 2011 & $\begin{array}{l}\text { Al6 - Gerenciar mudanças } \\
\text { DS10 - Gerenciar problemas } \\
\text { P010 - Gerenciar projetos } \\
\text { Al7 - Instalar e homologar soluções e mudanças }\end{array}$ & Número de mudanças registradas \\
\hline 2013 & DS1 - Definir níveis de serviço & \\
\hline
\end{tabular}

Fonte: Elaborado pelas autoras.

Ademais, a gestão eficaz de desempenho de TI exige, segundo as diretrizes do Cobit, um processo de monitoramento, que inclui a) a definição de indicadores de desempenho relevantes, b) informes de desempenho sistemáticos e oportunos e c) uma pronta ação em relação aos desvios encontrados.

Em relação ao primeiro aspecto, verifica-se que já foram adotados no TRE/SC indicadores de desempenho e que eles estão fornecendo informações importantes para o processo decisório dos gestores de TI. No que diz respeito ao segundo item, verifica-se que os relatórios de gestão do TRE/SC ainda não apresentam indicadores de desempenho para consubstanciar os resultados de TI, conforme preveem as melhores práticas de governança de TI. Já em relação ao terceiro ponto, verifica-se que, em algumas situações, as causas dos problemas não são identificadas imediatamente, tornando-se as ações de melhoria defasadas em relação ao momento em que os problemas ocorrem.

Constata-se, com base nesses resultados, que não há um monitoramento dos processos, uma vez que, segundo Luciano e Testa (2011), monitorar os processos implica a criação de uma série de indicadores de controle, estabelecendo métricas e pontos de controle. Isso permite que a organização possa fazer correções pontuais que se fizerem necessárias. Queiroz (2006) complementa assinalando que a falta de controle efetivo dessas ações resulta na perda de recursos investidos e na percepção tardia de resultados negativos.

A partir da análise dos dados coletados até esse momento, buscou-se comparar os resultados dos dados documentais com as percepções dos gestores operacionais acerca do impacto gerado pela implementação dos processos de governança de TI no TRE/SC. 
Nesse aspecto, procedeu-se à coleta de dados realizada por meio de entrevistas com os gestores operacionais da STI do TRE/SC, que buscou identificar sua percepção em relação: a) à implementação dos processos de governança de TI, propriamente dita; b) à mudança gerada; c) aos aspectos que trouxeram melhorias ou dificuldades; d) às vantagens e desvantagens do processo, bem como e) às principais falhas percebidas.

Em relação às principais diferenças percebidas pelos gestores operacionais com a implementação dos processos de governança de TI, constatou-se que os entrevistados foram unânimes em apontar o aumento da eficiência, da agilidade e da qualidade dos serviços disponibilizados pela Central de Serviços de TI aos usuários, percepção alinhada aos dados obtidos na pesquisa documental, que indicam uma preocupação dos gestores do TRE/SC em mensurar o desempenho relacionado ao processo DS8.

A percepção dos participantes vai ao encontro do que defendem Jaeger-Neto e colaboradores (2009) e Tarouco e Graeml (2011). Para os autores, a governança de TI pode influenciar significativamente no desempenho organizacional, uma vez que agrega valor ao negócio e possibilita uma gestão equilibrada do risco com o retorno do investimento.

Cabe lembrar que, com base nos achados de Tarouco e Graeml (2011), é possível afirmar que a adoção de um modelo de melhores práticas de TI pode estar diretamente relacionada com o aumento da visibilidade dos gestores sobre o retorno de investimentos em TI e ao aumento do controle e da qualidade dos serviços prestados pela TI, ou seja, a aplicação de governança leva a organização ao cumprimento de tais objetivos com sucesso.

No que tange às principais mudanças pós-implementação dos processos de governança de TI baseadas no Cobit percebidas pelos gestores operacionais, verificou-se que 67\% dos entrevistados consideraram uma mudança significativa a formação de uma visão mais gerencial da TI, que, por meio de dados concretos, obtidos por meio de indicadores de desempenho, possibilita uma tomada de decisão mais efetiva.

Em concordância com a maioria dos participantes, Fernandes e Abreu (2008) apontam que a avaliação de desempenho constitui um dos alicerces da governança de TI, uma vez que traduz estratégias em ações para atingir objetivos mensuráveis.

Por outro lado, 33\% dos entrevistados encontraram dificuldades em perceber mudanças, por se considerarem lotados em uma área muito operacional - o que reflete possivelmente uma falta de clareza por parte desses gestores quanto às estratégias da organização e uma falta de comunicação sobre os objetivos estratégicos, as diretrizes e as metas da organização por parte dos gestores de nível tático.

Sortica e Graeml (2009) enfatizam que, para haver um efetivo desdobramento da estratégia corporativa definida no planejamento estratégico para os demais níveis hierárquicos, é preciso haver um alinhamento interno no nível técnico-operacional, bem como uma ligação com os altos níveis gerenciais. Caso isto não ocorra, a fragilidade estrutural dali decorrente pode impedir a geração de novas ações estratégicas e a elaboração de mapas causais para a identificação da eficiência da estratégia adotada.

Quando questionados sobre os pontos que melhoraram ou pioraram com a implementação dos processos de governança de TI, os entrevistados indicaram, entre os pontos positivos percebidos: a) agilidade na disponibilização dos serviços de TI; b) comunicação aos usuários 
sobre indisponibilidades de serviços; c) cumprimento do acordo de nível de serviço estabelecido; d) definição do catálogo de serviços de TI, em que foram estabelecidos critérios de acesso aos serviços, responsáveis pela gestão dos serviços e gestão dos processos; e) melhoria no processo de tomada de decisão, bem como f) atendimento às demandas atuais e negociações das demandas futuras. Como aspecto negativo foi apontada uma "burocratização" natural no fluxo de trabalho interno, porém exagerada em determinados momentos, gerando dificuldades na operação.

No que tange às vantagens e desvantagens da implementação da governança de TI no TRE/SC percebidas pelos gestores, destacaram-se como vantagens: a) agilidade na execução de atividades relacionadas ao processo DS8, devido ao mapeamento do processo, definição e consolidação dos fluxos de trabalho, ou seja, devido à maturidade do processo; b) monitoramento e soluções de problemas críticos; e c) melhoria no atendimento aos usuários, gerando menor índice de reclamações e mais confiança do usuário na área de TI como um todo. Como desvantagem foi indicada a sensação de atuação baseada em "tentativa e erro" percebida por alguns gestores (33\%) na execução das atividades relacionadas aos processos DS9, AI6 e AI7.

Quanto aos pontos que deveriam ser melhorados, as opiniões foram divergentes. Cerca de 33\% dos gestores apontaram que o foco da melhoria deveria ser o aprimoramento dos processos DS9 e DS10; outros 33\% indicaram melhorias nos processos AI6 e AI7 e os 33\% restantes consideraram a comunicação a principal falha da instituição, apontando gargalos quando os fluxos de trabalho necessitam de aprovações de superiores.

Por fim, ao serem questionados sobre as principais falhas percebidas após a implementação dos processos de governança de TI, os gestores foram unânimes em apontar falhas na comunicação entre os setores e entre diferentes níveis hierárquicos como o principal problema enfrentado pelo TRE/SC atualmente. A falha de comunicação está tanto na divulgação de estratégias, diretrizes e metas a serem cumpridas quanto nas operações diárias.

A falha de comunicação é um ponto preocupante a ser destacado na análise dos resultados, pois, em consonância com Van Grembergen, De Haes e Guldentops (2004), entende-se que os mecanismos de comunicação são fatores importantes para viabilizar um ou mais objetivos da governança de TI: diminuição de riscos, geração de valor para a instituição, garantia do alinhamento à estratégia da instituição, gestão de recursos de TI, mensuração do desempenho da TI e responsabilidade pelas decisões de TI.

Outros pontos considerados falhos foram: a centralização de informações por algumas áreas técnicas e o atendimento de demandas fora do fluxo dos processos de governança de TI advindas de níveis hierárquicos superiores.

Verifica-se, desse modo, que as percepções dos gestores estão restritas à visão operacional que eles possuem. Não há, na maioria dos casos, um entendimento mais amplo e sistêmico - o que dificulta uma percepção de governança no âmbito mais abrangente. Nesse sentido, infere-se que, de acordo com Sethibe, Campbell e McDonald (2007), o modelo mental dos participantes acerca dos processos implementados encontra-se mais próximo da definição de gestão de TI do que de governança de TI, uma vez que tais gestores não conseguem perceber a integração do foco das ações interna e externamente, obstacularizando, portanto, a visão de que os processos devem contemplar a organização como um todo. 
Ainda, em relação à análise dos dados, destaca-se que quatro dos oito processos mapeados e implementados na organização estão relacionados à dimensão suporte e entrega de serviços, em que a atuação dos gestores operacionais é mais comum. Essa é uma dimensão crítica, pois, segundo Sortica e Graeml (2009), o suporte e a entrega devem harmonicamente refletir a existência de um relacionamento entre esses dois processos básicos. No primeiro caso, da entrega dos serviços, deve-se ir além da definição de um novo serviço, demonstrando assim uma preocupação com os processos relacionados com a gerência de projetos. De modo complementar, o suporte ao serviço precisa estar relacionado à operação e à manutenção do serviço anteriormente ativado.

Diante desses aspectos levantados ao longo da análise dos dados, propõem-se algumas ações com intuito de melhorar o fluxo de trabalho interno e, consequentemente, a governança de TI do TRE/SC, quais sejam:

a) divulgação periódica, em um informativo de TI, dos resultados dos indicadores, não apenas para as áreas técnicas, mas para toda a organização, de forma a possibilitar maior transparência e entendimento de custos, benefícios, estratégias, políticas e níveis de serviços de TI, em conformidade com os requisitos de governança;

b) agendamento de reuniões periódicas com gestores de TI ou com grupo formalmente instituído para esse fim com intuito de verificar os resultados apresentados pelos indicadores, analisá-los em relação às metas definidas e estabelecer estratégias concretas para melhorálos, bem como analisar a causa-raiz dos problemas e iniciar ação corretiva para tratar as causas ocultas;

c) definição de um plano de comunicação que possibilite informar os gestores sobre os projetos que serão desenvolvidos, bem como as estratégias adotadas para que o fluxo de informação seja aprimorado, evitando desgastes entre as áreas técnicas;

d) idealização de pesquisa para identificar o nível de satisfação da alta direção e das entidades de governança com os relatórios de desempenho demonstrados;

e) fortalecimento da integração entre as equipes técnicas, de forma que todos desenvolvam uma visão integrada e completa dos processos de governança de TI, de maneira tal que cada equipe garanta a entrega adequada do serviço para a próxima etapa do processo, numa visão sistêmica.

A partir de tais ações objetiva-se melhorar os processos de governança de TI que ainda não possuem um nível de maturidade adequado, promovendo uma melhoria gradual e contínua nos fluxos de trabalho internos, atenuando assim as falhas de comunicação, a centralização de informações e o atendimento prioritário de demandas fora do fluxo dos processos principais problemas enfrentados atualmente pelo TRE/SC, segundo a percepção dos gestores operacionais da STI.

Destaca-se, por fim, que, com a mudança do corpo diretivo do TRE/SC ocorrida em fevereiro de 2013, algumas iniciativas começaram a ser tomadas, no sentido de promover o 
compartilhamento das decisões de TI com os demais dirigentes da organização. Iniciaram a partir daquele ano as reuniões mensais do Comitê Gestor de Tecnologia da Informação, nas quais se passaram a avaliar conjuntamente questões relacionadas à contratação de bens e serviços de TI, ao planejamento estratégico de TI, à definição de plataforma computacional e de sistemas utilizados na organização, entre outras. Tal iniciativa está alinhada ao estudo de Mendonça e colaboradores (2013), que afirmam que o alinhamento (negócio e TI) nas decisões ocorre mais frequentemente sobre decisões que envolvem necessidades de aplicações de negócio e de investimentos, sendo esse compartilhamento de decisões entre gestores de negócio e de TI mais comum nas organizações públicas. Todavia, considerando a limitação temporal deste estudo (março de 2013), não foi possível verificar os efeitos que tais iniciativas promoveram na organização.

\section{Conclusão}

Verifica-se uma tendência da APF em uniformizar as ações empreendidas pela administração pública, no sentido de aprimorar os processos de governança de TI, buscando promover: a) o compartilhamento de decisões de TI com os demais gestores e com a alta direção; b) o estabelecimento de regras; e c) a definição de uma gestão de processos mais eficiente, eficaz e efetiva.

Nesse aspecto, o TRE/SC tem empreendido esforços no sentido de atender às recomendações dos órgãos superiores no que tange à implementação da governança de TI, iniciando sua adoção a partir da implementação do Planejamento Estratégico de TI (PO1), em março de 2010, seguido pelo mapeamento e pela implantação dos processos de gerenciamento da CSTI e incidentes (DS8) e gerenciamento da configuração (DS9). Em 2011 foram concluídas as implantações dos processos de gerenciamento de mudanças (AI6), gerenciamento de problemas (DS10), gerenciamento de projetos (PO10) e gerenciamento de instalações e homologações de soluções e mudanças (AI7). Já no início de 2013 foi implementado o processo de gerenciamento de acordo com o nível de serviço, totalizando oito processos.

Ainda, atendendo a um dos pilares da governança de TI, o TRE/SC implementou juntamente com os processos de governança a sua mensuração, definindo indicadores de desempenho que avaliam a eficiência, a eficácia e a efetividade dos serviços prestados. Embora o estudo documental tenha constatado que apenas dois processos possuam indicadores relacionados, destaca-se a importância desses indicadores por estarem associados diretamente à disponibilização de serviços de TI aos usuários e, consequentemente, à sociedade — principal "cliente" dos serviços prestados pelo poder público.

Com base na análise documental, constatou-se que o TRE/SC está alinhado às diretrizes dos órgãos de controle quanto à implementação da governança de TI. No entanto, buscando compreender a efetividade dessa implementação nas rotinas de trabalho dos gestores operacionais da STI do TRE/SC, coletaram-se, por meio de entrevistas, dados que permitissem compreender a percepção desses gestores acerca dos reflexos gerados por essa mudança no órgão.

Como resultados da pesquisa constatou-se que, na percepção dos gestores operacionais da STI, houve, após a implementação das melhores práticas de governança de TI, aumento da 
eficiência, da agilidade e da qualidade dos serviços disponibilizados pela CSTI aos usuários — refletindo positivamente na qualidade dos serviços disponibilizados. Identificou-se, ainda, a formação de uma visão mais gerencial da TI, que por meio de indicadores de desempenho proporciona uma tomada de decisão mais efetiva.

Embora os gestores tenham percebido melhoras significativas relacionadas a alguns processos, também indicaram pontos falhos notados após a implementação dos processos Cobit atrelados, especialmente, à comunicação entre as áreas técnicas e entre elas e os níveis superiores, à centralização de informações por algumas áreas e ao descumprimento dos fluxos dos processos advindos de mudanças provocadas por níveis hierárquicos superiores.

Cabe destacar que os gestores operacionais possuem, ainda, uma visão limitada em relação à governança de TI. Em outros termos, as percepções dos participantes estão intimamente atreladas às suas atuações na organização, faltando uma visão mais ampla e corporativa da governança de TI.

Conclui-se, portanto, este estudo afirmando que há um alinhamento entre os dados obtidos na pesquisa documental e os dados obtidos por meio de entrevistas, e que a percepção dos gestores operacionais da STI do TRE/SC é positiva em relação à implementação da governança de TI.

Destaca-se ainda que o presente estudo traz importantes contribuições para o desenvolvimento do conhecimento acerca da governança de TI nas organizações públicas, especialmente relacionadas ao impacto que esta gera no âmbito operacional dessas organizações.

Para estudos futuros, sugere-se, de forma mais ampla, desenvolver estudos semelhantes em outros órgãos da administração pública e em diferentes áreas de atuação, buscando assim traçar um panorama da governança de TI no setor público. De forma mais específica, considera-se também oportuno realizar uma análise da percepção do usuário dos serviços de TI em relação às mudanças ocorridas após a implementação das melhores práticas de governança de TI no TRE/SC.

Por fim, sugere-se também que se investigue o atual nível de maturidade do modelo de governança de TI do TRE/SC a partir da utilização do CobiT® Assessment Process (CAP). Assim, a capacidade para atender aos objetivos dos processos de negócio será avaliada e, a partir do resultado dessa avaliação, poderão ser planejadas ações para atingir o nível ideal de maturidade do processo.

\section{Referências}

ADACHI, Emília S. Governança de TI: análise crítica das práticas existentes em uma empresa estatal do setor de TI. Dissertação (mestrado em engenharia da produção) — Pós-Graduação em Engenharia de Produção, Universidade Federal do Rio Grande do Sul, Porto Alegre, 2008. Disponível em: <www. lume.ufrgs.br/bitstream/handle/10183/14822/000667045.pdf>. Acesso em: 31 jan. 2014.

ALVARES, Elismar; GIACOMETTI, Celso; GUSSO, Eduardo. Governança corporativa: um modelo brasileiro. Rio de Janeiro: Elsevier, 2008. 
ARMANI, Domingos. Como elaborar projetos? Guia prático para elaboração e gestão de projetos sociais. Porto Alegre: Tomo Editorial, 2008.

BRANDIÃO, Hugo J. et al. Administração pública. Florianópolis: Departamento de Ciências da Administração/UFSC, 2008.

BRASIL. A estrutura do Estado. Disponível em: <www.brasil.gov.br/sobre/o-brasil/estrutura/poderjudiciario >. Acesso em: 19 mar. 2013.

CARVALHO, Marcelo R. C. de. Gestão do conhecimento na implantação de processos de gestão da tecnologia da informação. Dissertação (mestrado) - Universidade Católica de Brasília, Brasília, 2005.

COURY, Wilson B. Poder e informação. Disponível em: <www.timaster.com.br/revista/artigos/ main_artigo.asp?codigo=424>. Acesso em: 12 jul. 2011.

DUMONT, Danilo M. RIBEIRO, José A.; RODRIGUES, Luiz A. Inteligência pública na era do conhecimento. Rio de Janeiro: Revan, 2006.

FAGUNDES, Eduardo M. Cobit: um kit de ferramentas para gestão de TI. 2009. Disponível em: <www.efagundes.com/Artigos/COBIT.htm>. Acesso em: 20 abr. 2013.

FERNANDES, Aguinaldo A.; ABREU, Vladimir F. de. Implantando a governança de TI: da estratégia à gestão dos processos e serviços. 2. ed. Rio de janeiro: Brasport, 2008.

FQN. Free Quality Network. Projeto de implantação do modelo de gestão Itil. Disponível em: <www.scribd.com/doc/3145173/Projeto-de-Implantacao-do-Modelo-Gestao-ITIL>. Acesso em: 28 out. 2010.

IBGC. Instituto Brasileiro de Governança Corporativa. Código das melhores práticas da governança corporativa. 4. ed. São Paulo: IBGC, 2009.

ISACA. COBIT framework for IT governance and control. Disponível em: <www.isaca.org/KnowledgeCenter/COBIT/Pages/Overview.aspx>. Acesso em: 22 dez. 2010.

ITGI. Information Tecnology Governance Institute. COBIT 4.1. USA, 2007. Disponível em: <www. itgi.org >. Acesso em: 2 maio 2013.

JAEGER-NETO, José et al. A percepção dos gestores de TI em relação às práticas de governança de TI adotadas em empresas do Rio Grande do Sul. Revista Eletrônica de Sistemas de Informação, v. 8, n. 1, p. 1-18, 2009.

KEINERT, Tânia M. M. Administração pública no Brasil: crises e mudanças de paradigmas. 2. ed. São Paulo: Annablume; Fapesp, 2007.

LUCIANO, Edimara M.; TESTA, Mauricio G. Controles de governança de tecnologia da informação para a terceirização de processos de negócio: uma proposta a partir do Cobit. JISTEM (Online), São Paulo, v. 8, n. 1, p. 237-262, 2011. Disponível em: <www.scielo.br/scielo.php?script=sci_ arttext\&pid=S1807-17752011000100012\&lng =pt\&nrm=iso $>$. Acesso em: 31 jan. 2014.

LUNARDI, Guilherme L.; BECKER, João L.; MAÇADA, Antônio C. G. Governança de TI e seus mecanismos: uma análise da sua disseminação entre as empresas brasileiras. In: ENCONTRO DA ANPAD, 2009, São Paulo. Anais... São Paulo: Anpad, 2009. p. 1-16. 
LUNARDI, Guilherme L.; BECKER, João L.; MAÇADA, Antônio C. G. Um estudo empírico do impacto da governança de TI no desempenho organizacional. Produção, v. 22, n. 3, p. 612-624, maio/ago. 2012.

LUNARDI, Guilherme L.; DOLCI, Pietro C. Governança de TI e seus mecanismos: uma análise da sua disseminação entre as empresas brasileiras. In: ENCONTRO NACIONAL DE ADMINISTRAÇÃO DA INFORMAÇÃO — ENADI, II, 2009, Recife. Anais... Recife:, EnADI, 2009. p. 1-14.

MENDONÇA, Cláudio M. C. de et al. Governança de tecnologia da informação: um estudo do processo decisório em organizações públicas e privadas. Rev. Adm. Pública, Rio de Janeiro, v. 47, n. 2, p. 443-468 mar./abr. 2013. Disponível em: <www.scielo.br/scielo.php?script=sci_arttext\&pid=S0034$76122013000200008 \& \operatorname{lng}=$ pt\&nrm =iso $>$. Acesso em: 31 jan. 2014.

PIRES, José C. S.; MACÊDO, Kátia B. Cultura organizacional em organizações públicas no Brasil. Rev. Adm. Pública, Rio de Janeiro, v. 40, n. 1, p. 81-106, jan./fev. 2006.

PREIS, Thiago A. Lista de verificação na implantação do CMMI-DEV 1.2 em integrações entre sistemas. Monografia (especialização em informática, ênfase em tecnologia da informação) - Universidade Federal do Paraná, Curitiba, 2011.

QUEIROZ, Leonardo G. de. Efetividade de sistemas de medição de desempenho organizacional: proposição e teste de critérios de efetividade. Dissertação (mestrado em administração de empresas) — Centro Universitário Positivo, Curitiba, 2006.

RODRIGUES, Leonel C.; MACCARI, Emerson A.; SIMOES, Sergio A. O desenho da gestão da tecnologia da informação nas 100 maiores empresas na visão dos executivos de TI. JISTEM J.Inf.Syst. Technol. Manag. (Online), v. 6, n. 3, p. 483-506, 2009.

RODRÍGUEZ, Martins V. R.; VIEIRA, Daniele M. Governança de TI no setor público — caso Dataprev. Produção Online: Revista Científica Eletrônica de Engenharia de Produção, Florianópolis, v. 7, n. 7, p. 207-225, dez./abr. 2007.

ROHWEDER, Adriana K. A governança de TI e a agregação de valor ao negócio: estudo de caso numa indústria de Joinville. 2007. Disponível em: <www.tede.udesc.br/tde_busca/arquivo. php?codArquivo=1208>. Acesso em: 11 mar. 2013.

SETHIBE, Tsholofelo; CAMPBELL, John; MCDONALD, Craig. IT Governance in public and private sector organizations: examining the differences and defining future research direction. In: AUSTRALASIAN CONFERENCE ON INFORMATION SYSTEMS IT GOVERNANCE IN THE PUBLIC SECTOR, 2007, Toowoomba.

SOFTWARE ENGINEERING INSTITUTE (SEI). CMMI@ para desenvolvimento versão 1.2: melhoria de processos visando melhores produtos. Pittsburgh, Pensilvânia, EUA: Carnegie Mellon University, ago. 2006.

SORTICA, Eduardo A.; GRAEML, Alexandre R. Critérios de efetividade da governança de TI: o caso de uma empresa brasileira do setor de telecomunicações. Faces R. Adm., Belo Horizonte, v. 8, n. 1, p. 11-30, jan./mar. 2009. 
TAROUCO, Hiury H.; GRAEML, Alexandre R. Governança de tecnologia da informação: um panorama da adoção de modelos de melhores práticas por empresas brasileiras usuárias. $R$. Adm., São Paulo, v. 46, n. 1, p. 7-18, jan./mar. 2011.

TCU. Tribunal de Contas da União. Acórdão 1603/2008-Plenário. Levantamento de auditoria. Situação da governança de TI na Administração Pública federal. Ausência de planejamento estratégico institucional. Deficiência na estrutura de pessoal. Tratamento inadequado à confidencialidade, integridade e disponibilidade das informações. Recomendações. Brasília, 2008. Disponível em: $<$ www.jf.jus.br/cjf/tecnologia-da-informacao/gestao-documental/tcu/acordao_tcu_-_13-08-2008. pdf/view>. Acesso em: 8 mar. 2013.

TCU. Tribunal de Contas da União. Relatório de levantamento. Avaliação da governança de tecnologia da informação na administração pública federal. Constatação de precariedades e oportunidades de melhoria. Determinações, recomendações e comunicações. Acordão AC-2308-33/10-P. Brasília, 2010. Disponível em: < http://portal2.tcu.gov.br/portal/page/portal/TCU/comunidades/ tecnologia_informacao/pesquisas_governanca/Relat\%C3\%B3rio\%20do\%20Levantamento\%20 Governan\%C3\%A7a\%20de\%20TI\%202010.pdf>. Acesso em: 8 mar. 2013.

TRESC. Tribunal Regional Eleitoral de Santa Catarina. Intranet. Disponível em: <intranet.tre-sc. gov.br>. Acesso em: 2 jul. 2012.

VAN BON, Jan; POLTER, Selma; VERHEYEN, Tieneke. ISO/IEC 20000: uma introdução. ITSM LIBRARY: Van Haren Publishing, 2009. Disponível em: < http://books.google.com.br/books?id=f $\mathrm{mXp0ilk2MkC \& printsec}=$ frontcover\&hl $=\mathrm{pt}-\mathrm{BR} \&$ source $=\mathrm{gbs} \_g e \_s u m m a r y \_r \& c a d=0 \# \mathrm{v}=$ onepage $\& q \& f=$ false $>$. Acesso em: 17 fev. 2014.

VAN GREMBERGEN, Wim; DE HAES, Steven; GULDENTOPS, Erik. Structures, processes and relational mechanisms for IT governance. In: VAN GREMBERGEN, Wim. Strategies for information technology governance. Hershey: Idea Group Publishing, 2004.

WEILL, Peter; ROSS, Jeanne W. Governança de TI, tecnologia da informação. São Paulo: M. Books do Brasil Editora Ltda., 2006.

WORTHEN, Blaine R.; SANDERS, James; FITZPATRICK, Jody. Avaliação de programas. São Paulo: Gente, 2004.

ZANELLA, Liane C. H. Metodologia de estudo e de pesquisa em administração. Florianópolis: Departamento de Ciências da Administração/UFSC; CAPES; UAB, 2009.

Rosangela Klumb é mestre em administração pela Universidade do Estado de Santa Catarina e ocupa o cargo de técnica judiciária do Tribunal Regional Eleitoral de Santa Catarina. E-mail: rose.klumb@ gmail.com.

Beatriz Marcondes de Azevedo é doutora em engenharia de produção e coordenadora de tutoria do curso de especialização EGS/EaD da Universidade Federal de Santa Catarina. E-mail: biabizzy@gmail.com. 